\title{
Neurilemmoma of Lateral Nasal Wall
}

\author{
Jyotsna Naresh Bharti, Parul Gautam, Prerna Arora
}

\begin{abstract}
Neurilemmoma is a benign tumour of nerve sheath origin that can arise from myelinated nerve. The Head and neck is the most frequent site involved and other sites are scalp, face, oral cavity, pharynx, larynx, trachea and ear. Neurilemmoma usually occur as solitary lesions and in association with NF type 2. Malignant transformation is very rare. We report a case of 18 year old male presented with complaint of nasal obstruction and swelling in right side of nose. We discuss the clinical presentation, histologic features, and therapeutic options for such a rare benign lesion. (Biomed J 2015;38:269-270)
\end{abstract}

\section{Key words: Schwannoma, S-100, neural, paranasal sinus}

W e describe the clinical, pathological, and radiological findings of an adolescent male who presented with swelling of right side of the nose. An 18-year-old male presented with the complaint of nasal obstruction and swelling in the right side of the nose for 6 months. Rhinoscopy revealed a small polypoidal mass in the right nasal cavity reaching till vestibule with decreased patency on the right side. The contrast-enhanced scan of paranasal sinus revealed a well-defined heterogeneous enhancing soft tissue mass arising from the lateral nasal wall, expanding and abutting the nasal septum and extending to the medial wall of right maxillary sinus. There was no evidence of bony erosion, intracranial extension, and involvement of other sinuses identified [Figure 1A]. The radiological features suggested the possibility of mucosal polyp or soft tissue tumor. The complete excision of mass was carried out by endoscopic sinus surgery and no evidence of recurrence was seen for 1 year postoperatively. Grossly well-encapsulated, partly mucosa-covered soft tissue mass was received, measuring 321 , which was mass firm, gray white, and homogenous on cut section. Multiple sections examined revealed unremarkable pseudostratified epithelium [Figure 1B]; subepithelium showed hypocellular and hypercellular lesion [Figure 1C] comprising spindle cells with elongated nuclei lined up in a palisading manner with formation of Verocay body [Figure 1C]. No mitosis and nuclear pleomorphism was seen. The tumor cells were reactive for S-100 protein [Figure 1D] and negative for desmin and smooth muscle actin. The final diagnosis of neurilemmomas without intracranial extension was made. Neurilemmomas are neoplasms that arise from the proliferation of Schwann cells

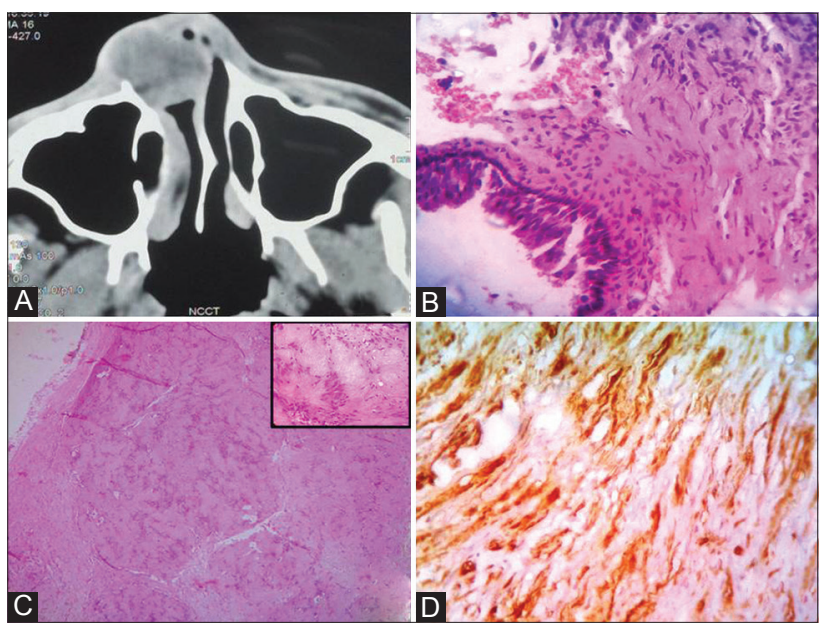

Figure 1: (A) Non-contrast computed tomography paranasal sinus showed well-defined heterogeneous enhancing soft tissue mass arising from lateral nasal wall, expanding and abutting the nasal septum and extending to the medial wall of right maxillary sinus. (B) Unremarkable respiratory mucosa. (H and E, $\times 400$ ). (C) A hyper- and hypocellular area with Verocay body (inset) ( $\mathrm{H}$ and $\mathrm{E}$, $\times 400)$. (D) Tumor cells show strong reactivity with S-100 $(\times 400)$

present in the peripheral nerve sheath of myelinated nerves. They are commonly located in the head and neck region, extensor areas of the extremities, mediastinum, retroperitoneum, and paraspinal region. ${ }^{[1]}$ The incidence in the head and neck region accounts for $25-45 \%$ of cases; however, involvement of nose and paranasal sinus is rare and can be seen in $4 \%$ of cases. ${ }^{[2]}$

Computed tomography scan may help to distinguish neurilemmomas from malignancies as they can cause bone remodeling by pressure and this behavior can lead to mis-

From the Department of Pathology, Maulana Azad Medical College, New Delhi, India

Received: Aug. 11, 2013; Accepted: Jun. 20, 2014

Correspondence to: Dr. Jyotsna Naresh Bharti, Department of Pathology, Maulana Azad Medical College, India. Bahadur Shah Zafar Marg, New Delhi-110002, India. Tel: 91-9899047062; E-mail: jyotsnamamc@ gmail.com

DOI: $10.4103 / 2319-4170.137770$ 
diagnosis as a malignant process. ${ }^{[3]}$ Grossly, on cut section, the tumor lacked uniformity and microscopically, the most characteristic feature of the neurilemoma was regimentation of the nuclei, often called palisading in which parallel arrangement of nuclei with intervening nucleus-free zones were seen. Other features included encapsulation, microcystic degeneration, thickening, and hyaline change in the walls of the blood vessels called as hyaline cuffing. ${ }^{[4]}$ The treatment of choice in neurogenic tumors is a complete surgical excision that can be achieved endoscopically or through external approach depending on the localization and size of the lesion. ${ }^{[5]}$ Neurilemmoma should be considered as differential diagnosis for nasal cavity mass and thorough secti oning is required to look for mitotic activity and necrosis as its local aggressive behavior can mimic malignancy.

\section{REFERENCES}

1. Zhang PJ. Tumors and Tumor-Like Lesions of the Soft-Tissues. In: Khurana JS, McCarthy EF, Zhang PJ editors. Essentials in Bone and Soft-Tissue Pathology. New York: Springer; 2010. p. 159-216.

2. Hasegawa SL, Mentzel T, Fletcher CD. Schawannoma of the sinonasal tract and nasopharynx. Mod Pathol 1997;10:777-84.

3. Mannan AA, Singh MK, Bahadur S, Hatimota P, Sharma MC. Solitary malignant Schwannoma of the nasal cavity and paranasal sinuses: Report of two rare cases. Ear Nose Throat J $2003 ; 82: 638-40$.

4. Heard G. Nerve sheath tumours and Von Recklinghausen's Disease of the nervous system. Ann R Coll Surg Engl 1962;31:229-48.

5. Lo S, Ho WK. Schwannoma of the larynx-an uncommon cause of vocal cord immobility. Hong Kong Med J 2004;10:131-3. 